\title{
Single polymer composite sheets from polypropylene nonwoven fabric and films. Influence of processing conditions on final properties
}

\author{
Yamila V. Vazquez $^{1,2}$ | Luciana A. Castillo ${ }^{1,2} \quad \mid \quad$ Silvia E. Barbosa ${ }^{1,2}$ ()
}

${ }^{1}$ Planta Piloto de Ingeniería Química, PLAPIQUI (UNS-CONICET), Bahía

Blanca, Argentina

${ }^{2}$ Departamento de Ingeniería Química, Universidad Nacional del Sur (UNS),

Bahía Blanca, Argentina

\section{Correspondence}

Silvia E. Barbosa, Planta Piloto de Ingeniería Química, PLAPIQUI (UNSCONICET), Cno. La Carrindanga km. 7, Bahía Blanca 8000, Argentina.

Email: sbarbosa@plapiqui.edu.ar

\begin{abstract}
Single polypropylene (PP) composites from a film/nonwoven fabric/film was obtained by hot calendering in order to develop recyclable, flexible, and lowcost sheets. Processing temperature $\left(T_{\mathrm{p}}\right)$ influence on morphology and mechanical properties of developed single composites was analyzed. Two different values of roll temperature $\left(140\right.$ and $\left.150^{\circ} \mathrm{C}\right)$ were studied, keeping constant rotation speed and rolls distance. Results revealed notable differences in materials microstructure induced by a difference of only $10^{\circ} \mathrm{C}$ in $T_{\mathrm{p}}$. Sheets obtained at $140^{\circ} \mathrm{C}$ presented a well-defined film/nonwoven fabric/film structure, meanwhile the highest $T_{\mathrm{p}}$ led to a greater melting extent of external films which penetrate into the fabric, creating a more compact structure. Moreover, results confirmed that changes in $T_{\mathrm{p}}$ can induce a differential mechanical performance showing higher strength, and ductility in sheets processed at $150^{\circ} \mathrm{C}$. Homogeneous sheets with good mechanical behavior, proper nonwoven fabric/films adhesion, and uniform thickness were obtained.
\end{abstract}

\section{K E Y W O R D S}

composites, mechanical properties, reinforcement, thermal properties

\section{1 | INTRODUCTION}

Development of single polymer composites (SPCs) has emerged as a solution to an essential problem of composites related to the quality of adhesion between matrix and reinforcement. In this sense, SPC preserve the main objective of traditional composites concerning the stress transfer from the "weaker" matrix to the "stronger" reinforcement, where the latter could have one-, two-, or three-dimensional structure. Four decades ago, Capiati and Porter ${ }^{[1]}$ introduced SPC term referring to composites constituted by materials made from the same resin. Main requirement for a polymer to constitute an SPC is its capability to behave as both, isotropic matrix and anisotropic reinforcement (fiber, tapes, and so on) with different melt temperatures. Usually, fibers have a crystalline morphology highly oriented and then, higher melting temperature $\left(T_{\mathrm{m}}\right)$ than the matrix..$^{[2,3]}$ During composite production, only fibers surface is melted with bulk matrix, preserving their structure and, consequently, mechanical properties. Taking into account that both components are constituted by the same resin, fiber matrix adhesion is the best possible since the same molecules are entangled between them. Another strong advantageous property of SPC is their recycling capability by reprocessing with the same operations than base polymer. ${ }^{[4-6]}$ In this way, the most used resins to develop SPC are semicrystalline polymers such us polypropylene (PP), polyethylene (PE), and polyethylene terephthalate (PET), among others. ${ }^{[7]}$ Reinforcing components have a highly anisotropic character coming from their processing manufacture. Then, in cases where an 
isotropic behavior is required, this characteristic could be a disadvantage. For this reason, several works reported the use of woven fabrics (made from fibers or tapes) which are layered in different directions to obtain a more isotropic SPC ${ }^{[8]}$ A low-cost option to reach isotropic SPC behavior, is by using nonwoven fabric as a reinforcement although there is scarce studies about this. ${ }^{[9]}$ Nonwoven fabrics are defined as a web or batt of randomly oriented fibers thermally bonded by surface adhesion and a repetitive pattern of hot points. ${ }^{[10]}$ However, mechanical performance of SPC sheets from nonwoven fabric cannot be extrapolated to SPC sheets from layered woven fabrics, then final applications are different.

In order to develop flexible, recyclable, and cheap sheets, a promissory alternative is to generate a SPC by using a film/nonwoven fabric/film sandwiched structure. Another requirement for the sheet obtention is that they can be produced with a continuous and simple process. In general, SPC technology takes advantage of the strong dependence of polymer $T_{\mathrm{m}}$ on crystallization conditions, as well as, on SPC previous processing to obtain a certain orientation. ${ }^{[11]}$ These characteristics must be considered for the selection of both, fabrication process and processing conditions. It is well known that all semicrystalline polymers present crystallites with several degrees of perfection, leading to different $T_{\mathrm{m}}$. Consequently, polymers show a wide melting range, which is characterized by temperatures related to the onset, maximum and final fusion. Thus, temperatures close to the melting onset are well suited to produce SPC because it is expected that only a small amount of polymer would be melted. ${ }^{[12]}$ However, the narrow temperature processing window, generally only a few degrees, represents a disadvantage for SPC production. In this sense, high temperatures are not recommended in order to avoid melting of a large proportion of reinforcement, which irreversibly degrades reinforcing properties, such as strength. On the other hand, matrix is not melted enough at low temperatures, resulting in a poor adhesion with the reinforcement. Consequently, the processing variables adjustment is fundamental in order to tailor final properties of SPC sheet.

Film stacking followed by compression molding is the SPC fabrication process that allows a better control of matrix and fiber surface melting and, consequently, high adhesion. ${ }^{[13]}$ However, this semicontinuous process presents some disadvantages such as longer processing times and elevated labor costs. ${ }^{[8]}$ An alternative method to produce SPC using a continuous process is film stacking followed by hot calendering. In this way, calender simultaneously acts as a hot press and drawing system. An adequate balance among operating parameters is required to obtain a homogeneous product with adequate aspect, good mechanical behavior, proper adhesion among individual layers, as well as, a uniform thickness distribution.

Taking into account that processing conditions determines materials final properties, in the frame of the development of recyclable, flexible and low-cost SPC sheets; the aim of this work is to analyze the influence of calendering process conditions on structure and mechanical properties of SPC. In this sense, single PP composites from a film/nonwoven fabric/film was sandwiched by hot calendering. The considered operation conditions were calendering roll temperature, rolls gap, and draw speed. Structural aspects of SPC such as adhesion, voids, matrix penetration, and relative melting, were analyzed on fracture surface by scanning electron microscopy (SEM). PP crystalline morphology of fabric and films in SPC was analyzed by X-ray diffraction and differential scanning calorimetry (DSC). Moreover, normalized tensile and tear tests were carried out to determine mechanical properties. Relationship between morphology, crystalline structure, thermal, and mechanical properties of PP based SPC was deeply discussed in this work.

\section{2 | EXPERIMENTAL}

\section{1 | Materials}

Homopolymer PP films $(60 \mu \mathrm{m})$ from PS Film S.R.L. (Argentina) were used as external layers in SPC. According to the supplier information, films were obtained by blown film extrusion. PP nonwoven fabric (spunbond) were purchased from GTR (Argentina). The density of this fabric is $120 \mathrm{~g} / \mathrm{m}^{2}$ and the color is white.

\section{2 | SPCs processing}

\subsection{1 | Process description}

To develop a SPC, the nonwoven fabric was sandwiched between two films, as it can be observed in Figure 1 .

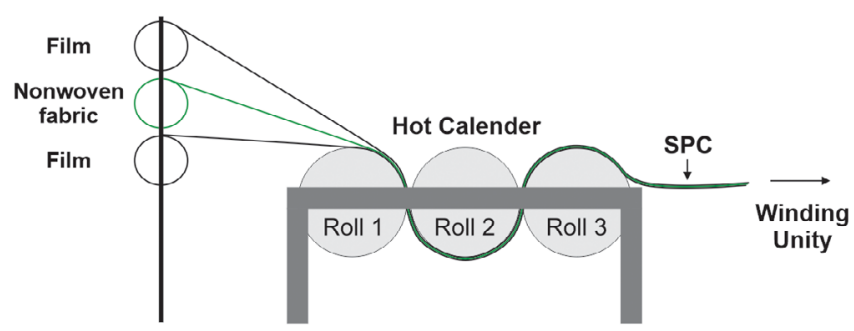

F I G U RE 1 Single polymer composite (SPC) processing [Color figure can be viewed at wileyonlinelibrary.com] 
These three layers (film/nonwoven/film) were fed into a pilot calender, constituted by three rolls with same dimensions (diameter: $40 \mathrm{~cm}$, width: $30 \mathrm{~cm}$ ) which are connected in series. Each roll can be heated independently up to $300^{\circ} \mathrm{C}$ and the gap between them is set by pneumatic closure. Then the laminate is tight in order to allow a better SPC consolidation. This is performed by a winding unity with a speed rate of $2.3 \mathrm{rpm}$. Consolidation of these three layers in one single sheet proceeds from typical hot calendering process as result of a balance among roll/winder speed, gap, and temperature.

\subsection{2 | Selection of processing parameters}

It is well known that the main key parameter in hot calendering process is the roll temperature. ${ }^{[14]}$ Then, in order to analyze the influence of this calendering parameter on SPC final performance, all the other processing conditions were kept constant for each assay. Several screening experiments to reproduce similar industrial production rates were performed to select roll/draw speed and gaps between rolls. The selected values were: $2 \mathrm{rpm}$ (equivalent to a production of 150 SPC meter per hour) and $500 \mu \mathrm{m}$, respectively. As a result of screening experiments, a preheating step was considered for a first SPC consolidation by sticking through polymer surface softening. Then, the first roll temperature was set at $90^{\circ} \mathrm{C}$ in all assays. Two series of experiments were performed with different processing temperatures $\left(T_{\mathrm{p}}\right)$. In this sense, the second and the third roll temperature was set at the same value: $140^{\circ} \mathrm{C}$, for the first series and $150^{\circ} \mathrm{C}$, for the second one. This temperature range was selected considering the melting behavior of both, PP film and fabric. Name of all analyzed samples are listed in Table 1.

\section{3 | Characterization}

Morphological structure of SPC was observed by SEM in a LEO EVO 40X VP electron microscope, using an accelerating voltage of $10 \mathrm{kV}$. Cryo-fracturing of SPC was carried out under liquid nitrogen in order to obtain an

TA B LE 1 Samples name

\begin{tabular}{|l|l|}
\hline Sample & Name \\
\hline Film & F \\
\hline Nonwoven fabric & NWF \\
\hline SPC processed at $140^{\circ} \mathrm{C}$ & SPC140 \\
\hline SPC processed at $150^{\circ} \mathrm{C}$ & SPC150 \\
\hline
\end{tabular}

accurate representation of microstructure. All samples were coated with thin layers of gold by using an argon plasma metallizer (sputter coater PELCO 91000) to make them conductive before observation.

Thermal behavior of F, NWF, and SPCs was studied by DSC in a Discovery DSC (TA Instruments) calorimeter. A heat/cool/heat test was performed on 8 to $11 \mathrm{mg}$ samples in a temperature range of $30-$ to $200^{\circ} \mathrm{C}$ at a rate of $10^{\circ} \mathrm{C} / \mathrm{min}$ under nitrogen atmosphere. Melting $\left(T_{\mathrm{m}}\right)$ and onset $\left(T_{\mathrm{o}}\right)$ temperatures were assessed for each material and composites. The first one corresponds to the maximum value of the melting peak. Meanwhile, $T_{\mathrm{o}}$ (according to ASTM D-3418:2003) is the intersection point between the extrapolated baseline and the inflectional tangent at the beginning of the melting peak. ${ }^{[15]}$ Both temperatures values for each sample were assessed using the TA Instruments Trios program (Waters Technologies Ireland Ltd. Version 4.3.0.38388).

Crystal structure identification of all samples were assessed by X-ray diffraction (XRD). A Philips PW1710 Xray diffractometer was used, which was provided with a tube, a copper anode, and a detector operating at $45 \mathrm{kV}$ and $30 \mathrm{~mA}$ with $2 \theta$ ranging from $5^{\circ}$ to $60^{\circ}$.

Mechanical properties of all samples were measured at $23^{\circ} \mathrm{C}$ using an Instron 5566 universal testing machine. Tensile tests were performed up to sample breakage using a crosshead speed of $10 \mathrm{~mm} / \mathrm{min}$ with a $10 \mathrm{~cm}$ gauge length and a load cell of $1 \mathrm{kN}$. Samples were cut into $25 \mathrm{~mm}$ wide strips according to ASTM D882. ${ }^{[16]}$

In addition, tear tests were performed using the aforementioned universal testing machine, with a constant crosshead speed of $250 \mathrm{~mm} / \mathrm{min}$ and an initial grip separation of $50 \mathrm{~mm}$. According to ASTM D-1938 ${ }^{[17]}$ standard test method, samples $(25 \times 75 \mathrm{~mm})$ with a slit at $12.5 \mathrm{~mm}$ were prepared. Tensile and tear properties were assessed in two directions with respect to the calendering draw, named machine direction (MD) and transverse direction (TD).

\section{3 | RESULTS AND DISCUSSION}

Figure 2 shows SEM micrographs at different magnifications of fracture surface corresponding to SPC obtained at both processing temperatures $\left(T_{\mathrm{p}}\right): 140$ and $150^{\circ} \mathrm{C}$. It can be observed significant structural differences between materials cross sections as a consequence of $T_{\mathrm{p}}$. The most evident difference between SPCs is the sheets thickness. The higher the temperature, the lower the thickness, as expected. From the measurements, thickness for SPC140 is 33\% higher than the corresponding to SPC150. The reason of this difference is based on the fact that processing at $150^{\circ} \mathrm{C}$ allows a higher films surface penetration within 

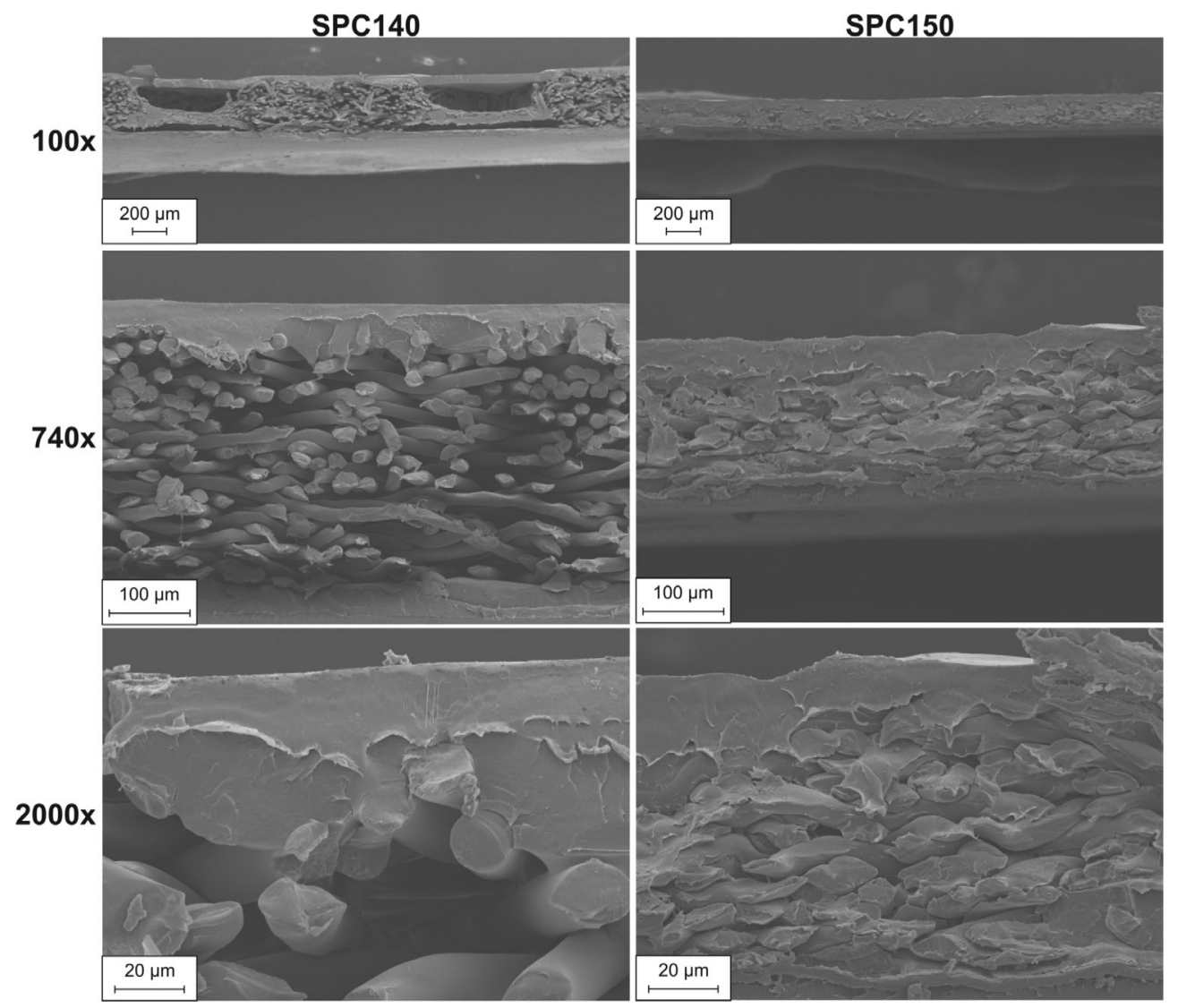

F I G URE 2 Scanning

electron microscopy micrographs of single polymer composites (SPC140 and SPC150) at different magnifications the fibers net of NWF as a consequence of a greater melting of the external layers.

Regarding the influence of $T_{\mathrm{p}}$ on SPCs microstructure, SPC140 presents a well-defined layered structure comprised of two outer $\mathrm{F}$ and a core of NWF (constituted by a net of fibers randomly distributed) in-between (Figure 2). Particularly, $T_{\mathrm{p}}=140^{\circ} \mathrm{C}$ allows the SPC core to remain intact as in the initial NWF. Additionally, it can be appreciated quasi-rectangular holes on the SPC sheets, which correspond to the NWF hot points. This holes arrangement, repeated periodically along the sheet surface, is a NWF feature that is not altered by the processing at $140^{\circ} \mathrm{C}$. On the other hand, SEM micrograph of SPC150 presents a more compact and integrated structure where SPC sheet layers cannot be clearly recognized (Figure 2). A rough core could be appreciated in this SPC cross section, evidencing the presence of fibers that corresponds to NWF.

More details concerning to SPCs structure could be observed at higher SEM magnifications. In this sense, SPC140 reveal a core constituted by fibers which conserve their circular shape, having homogeneous diameters around $18 \mu \mathrm{m}$ (Figure 2). Contrarily, the highest $T_{\mathrm{P}}$ leads to a SPC (SPC150) where the intermediate layer shows deformed and closer fibers, although the integrity of NWF is conserved.
Regarding the adhesion between $\mathrm{F}$ and NWF, the layer interface is clearly defined in SPC140 (Figure 2). Despite there is a surface junction between fibers and film, holes from NWF are conserved. In the case of SPC150, there is an evidence of an intimate contact between the core and the outer layers. This fact proceeds from the favored melting of external film layers by the higher $T_{\mathrm{p}}$ according to thermal behavior of PP films as will be discussed below. Clearly, a difference of $10^{\circ} \mathrm{C}$ in $T_{\mathrm{p}}$ induces notable differences in the overall morphology of SPC sheets that could affect their final properties.

Thermograms for F, NWF, and SPCs are presented in Figure 3. First heating curves (Figure 3A) give information about the influence of processing on the crystalline structure of SPC sheets, as well as, the crystalline morphology of $\mathrm{F}$ and NWF. Regarding $\mathrm{F}$ thermogram, it is possible to observe a single melting peak around $162^{\circ} \mathrm{C}$ which is associated to a single crystal population. This value is in agreement with the melting temperature for isotactic PP, reported by Manchado et al. ${ }^{[18]}$ Also, onset temperature $\left(T_{\mathrm{o}}\right)$, that gives information of melting start, is around $151.6^{\circ} \mathrm{C}$. On the other hand, NWF presents two overlapped peaks $\left(\sim 163\right.$ and $\left.166^{\circ} \mathrm{C}\right)$ which correspond to different crystals populations, being $T_{\mathrm{o}}=154.7^{\circ} \mathrm{C}$. This behavior could be related to melting events during NWF manufacturing, where fibers only suffer a partial melting 

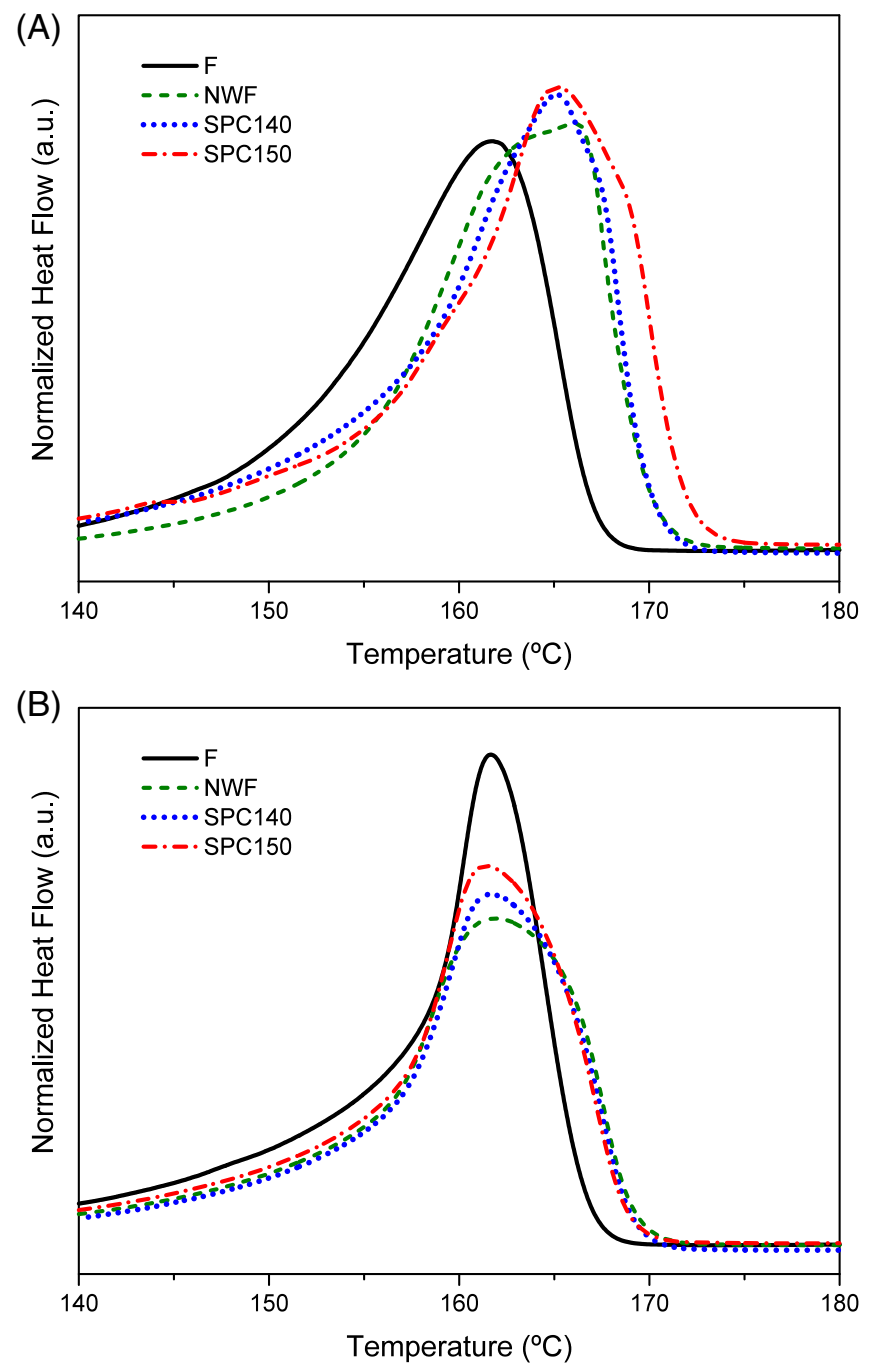

F I G U R E 3 Differential scanning calorimetry curves for film (F), fabric (NWF), and single polymer composites (SPC140 and SPC150) for: (A) first heating and (B) second heating [Color figure can be viewed at wileyonlinelibrary.com]

of fiber-fiber interphase. Also, through localized thermal compression (hot points), a surface repetitive pattern is introduced in order to obtain a cohesive nonwoven net, producing a differential melting along NWF. Then, higher $T_{\mathrm{m}}$ value proceeds from fibers melting and the lower one could be associated with the melting of recrystallized polymer after NWF fabrication process.

Regarding SPCs melting behavior (Figure 3A), two overlapped peaks are detected, evidencing that the structure of their components ( $\mathrm{F}$ and NWF) is conserved independently of $T_{\mathrm{p}}$. Onset temperature is 156.4 and $158.5^{\circ} \mathrm{C}$ for SPC140 and SPC150, respectively; being higher than the corresponding to F and NWF. This behavior proceeds from the melting contribution of imperfect crystals of film component in the sheet. Additionally, SPC150 presents a higher offset temperature than the other three samples (F, NWF, and SPC140). This fact corroborates the $F$ penetration on the NWF surface observed in Figure 2 since bigger amount of energy is necessary to melt this sheet. Moreover, the higher penetration of $\mathrm{F}$ in SPC150 than in SPC140 proceeds from the lower $T_{\mathrm{o}}$ value for $\mathrm{F}$ (Figure $3 \mathrm{~A}$ ). This behavior is in accordance with the presence of a bigger crystals population in SPC150.

In order to determine if polymer does not suffer degradation by the processing, thermograms from the second heating of DSC (Figure 3B) are analyzed, as the thermal history was erased. As expected, $T_{\mathrm{m}}$ is the same for $\mathrm{F}$, NWF, and sheets corroborating that the constitutive polymer is PP. This value is around $165^{\circ} \mathrm{C}$ which is associated to the melting of $\alpha$-phase PP. ${ }^{[19]}$ However, there is a difference in the thermal behavior between $\mathrm{F}$ and NWF samples being attributed to PP grade. Melting curves differences could be related to the variation in molecular weight distribution that generates differences in crystalline morphology, evidenced by the higher offset temperature of NWF and SPCs with respect to F. This fact indicates the presence of bigger crystals associated with longer polymer chains as in fibers which are present in NWF structure and thus, in SPCs. ${ }^{[20]}$

XRD spectra of F, NWF, and SPCs are presented in Figure 4. Major characteristic peaks of isotactic PP $\alpha$ phase can be appreciated in all samples at the following scattering angles $(2 \theta): 14.25,17.05,18.59,21.29,21.99$, 25.73 , and $28.57^{\circ}$. The assignment of these signals according to their reflection planes is included in Figure $4 .{ }^{[21-23]}$ Particularly, NWF and SPCs present a signal at $27.41^{\circ}$ which corresponds to the characteristic peak of the titanium dioxide rutile (R) phase, ${ }^{[24,25]}$ a typical white pigment used in polymer based materials. ${ }^{[26]}$ This peak corresponds to the maximum intensity signal of the $\mathrm{R}$ phase and it can be detected since the spectra region is

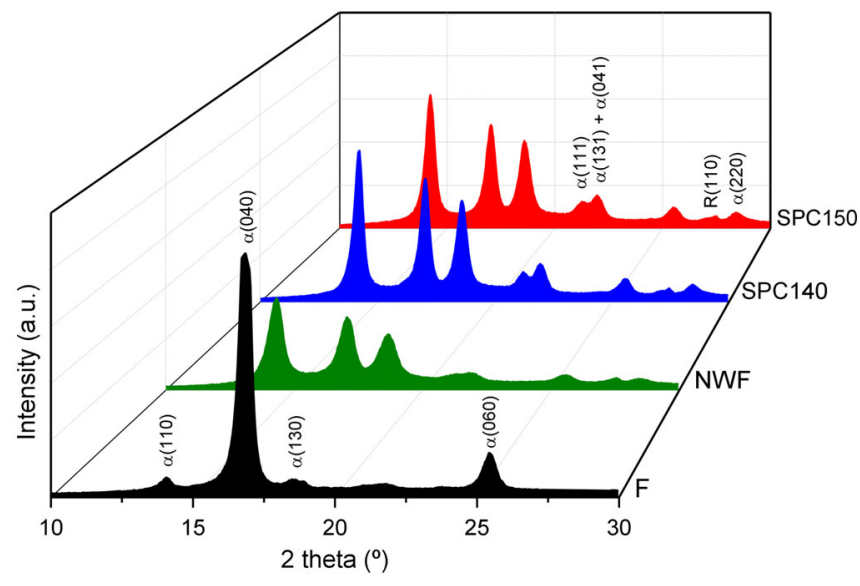

FI G U RE 4 X-ray diffraction spectra for film (F), fabric (NWF), and single polymer composites (SPC140 and SPC150) [Color figure can be viewed at wileyonlinelibrary.com] 
free of PP characteristic peaks. ${ }^{[27]}$ Also, it is reported that the main peak of anatase (A) phase is at $2 \theta=25.3^{\circ}$. $^{25]}$ However, the presence of the A phase cannot be corroborated in XRD spectra because there is a PP characteristic signal $\left(2 \theta=25.73^{\circ}\right)$ in the same region. ${ }^{[28]}$ On the other hand, differences in the relative intensity of XRD peaks among F, NWF, and SPCs are observed, which can be analyzed in terms of crystals orientation. In this sense, the intensity ratio of (040) reflection, $I(040)$, to that of (110) reflection, I(110), allows to assess the isotropy degree of the studied materials. According Rybnikar ${ }^{[29]}$ and Alonso et al, ${ }^{[30]}$ if $I(040) / I(110)$ ratio is between 0.54 and 0.77 , PP based material is highly isotropic. Regarding F spectra, it has a $I(040) / I(110)$ ratio of 12.2 , revealing a notable crystal orientation in (040) plane as a consequence of its processing, that is, blown film extrusion. ${ }^{[31]}$ The influence of the manufacturing process in the orientation of polymer crystals is proved by the fact that this ratio is far above from those values for isotropic materials. Concerning NWF, SPC140, and SPC150: they present $I(040) / I(110)$ ratio values in the range of 0.77 and 0.82. These results evidence that NWF and SPC sheets are quasi isotropic materials from the crystalline point of view. Particularly, the ratio for NWF demonstrates the random distribution of fibers along the fabric, although they have a highly anisotropic crystalline morphology by themselves. On the other hand, from XRD spectra of SPC140 and SPC150, it is possible to note that the (110), (040), and (130) reflection planes present higher intensities than those corresponding to NWF. Besides, they show the same tendency as the NWF ones: the higher $2 \theta$ value, the lowest the signal intensity of (110), (040), and (130), respectively (Figure 4). This fact indicates that the core (NWF) of SPCs has more influence than the films on final structure, as expected, because the higher mass contribution of NWF in sheets. Also, (111) and (131) + (041) signals became more notable in SPCs with respect to both, NWF and F. All these facts could be related to the contribution on crystal orientation by the calendering process.

Considering results obtained from DSC and XRD characterization, it is possible to conclude that for both $T_{\mathrm{P}}\left(140\right.$ and $\left.150^{\circ} \mathrm{C}\right), \mathrm{SPC}$ structure is preserved since $\mathrm{F}$ and NWF crystalline morphology is conserved. Taking into account that mechanical properties are directly related with microstructure, ${ }^{[32]}$ tensile and tear tests were carried out in order to analyze the influence of $T_{\mathrm{P}}$ in mechanical performance.

Concerning tensile mechanical properties, Figure 5 shows load-extension curves for F, NWF, and SPCs determined in MD and TD. These curves were considered instead of stress-strain ones since cross section of NWF and, consequently, SPC specimens present a considerable

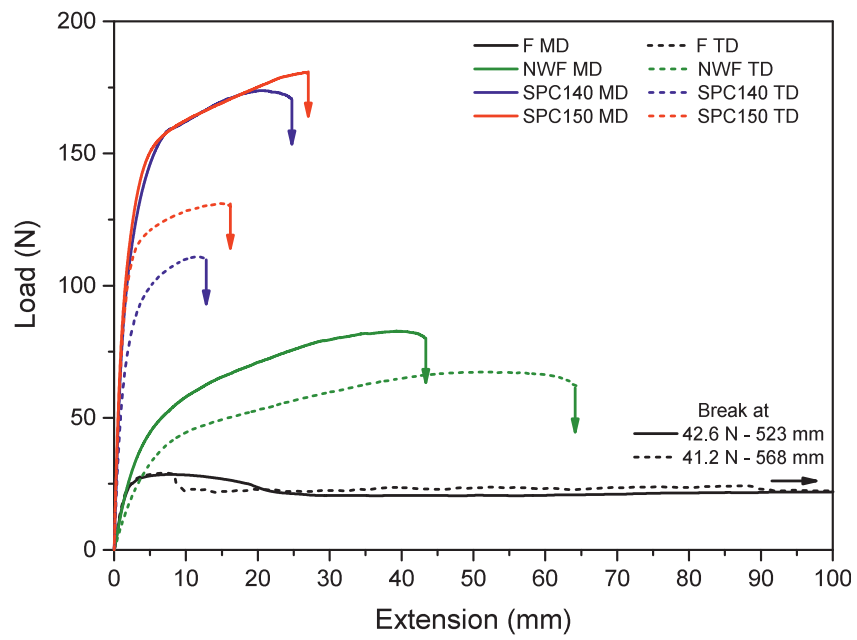

F I G U RE 5 Load-extension curves for film (F), fabric (NWF), and single polymer composites (SPC140 and SPC150) determined in machine (MD) and transverse (TD) direction [Color figure can be viewed at wileyonlinelibrary.com]

void fraction, as it can be observed previously by SEM. Thus, thickness measurement is not accurate which introduces notable errors in stress determination. In this way, the strength of studied materials is considered as the maximum force of the curve and the ductility as the extension at break. This kind of mechanical properties assessment better represents actual properties of the SPC sheets.

Regarding MD, mechanical behavior of $\mathrm{F}$ reveals a yield point given by the local maximum detected at low extension values. Moreover, a strain hardening occurs at the end of the curve, as it can be appreciated from the break load value included in Figure 5. This behavior is a consequence of the oriented polymer chains induced during film processing. ${ }^{[33]}$ On the other hand, mechanical performance of NWF MD is completely different from the corresponding to F MD, although both materials are constituted by PP. Fabric shows a considerably higher strength, but lower extension at break than F MD. This NWF mechanical pattern is still evident in both SPCs, corroborating that fabric structure is preserved after calendering. Differences in mechanical behavior between $F$ MD and NWF MD resides mainly on the final morphology given by their respective processing. In this sense, F is constituted by polymer chains which are strongly aligned by blown processing. Meanwhile, NWF is formed by a fiber assembly with large interconnected voids, establishing a continuous pattern throughout the fabric. Consequently, NWF presents a random microstructure as they are manufactured from a set of fibers consolidated by bonds of different nature, such as simple entanglement and local thermal fusion. ${ }^{[34]}$ This microstructure and the nonconsolidated fibers determine the higher 
strength and the less extension of NWF with respect to F MD.

With respect to SPCs, strength has been improved with respect to the fabric at both processing temperatures as a consequence of $\mathrm{F}$ layers addition. The strength of SPCs is higher than the corresponding of $F$ MD. However, extension of SPCs is lower not only to F MD, but also to NWF MD one. This behavior can be associated to a more hindered movement of fibers as a consequence of the film penetration into NWF during calendering at both $T_{\mathrm{p}}$. Moreover, SPC150 presents slightly higher strength and extension than SPC140. This fact is related to an F/NWF stronger interfacial adhesion by the increment of only $10^{\circ} \mathrm{C}$ in $T_{\mathrm{p}}$. These results confirm that changes in calendering temperature induce different SPC morphology as it was previously observed by SEM and assessed by DSC and XRD, resulting in different mechanical performances.

Load-extension curves for F, NWF, and both SPCs determined in transverse direction (TD) are shown in Figure 5. Mechanical pattern of F TD also reveals a yield point, showing an overall maximum at high extensions because of a hardening behavior, as occurred in MD. Overall mechanical behavior of NWF TD is similar to the observed in MD, presenting a lower strength but higher extension than F. Regarding both SPCs, similar load-extension curves as NWF TD can be observed, indicating that the fabric structure remains intact after calendering, as in MD. Mechanical properties of SPCs reveal a higher strength but lower extension than NWF. This behavior shows that final material is stronger than NWF TD. All mechanical properties of SPC150 TD have been improved with respect to SPC140 TD. Clearly, sheets processing at $150^{\circ} \mathrm{C}$ allows enhancing mechanical properties in both directions. However, this fact is much more evident in TD. There are two contributions to final mechanical behavior: processing direction and $T_{\mathrm{p}}$. When mechanical performance is evaluated in MD, processing direction predominates over the $T_{\mathrm{p}}$, consequently final properties show a slight variation with the increment of $T_{\mathrm{p}}$. On the other hand, in TD the major influence is given by temperature, resulting in greater differences between the SPCs at different $T_{\mathrm{p}}$.

Considering that tear behavior is relevant for sheet final applications and depends on calendering direction $^{[35]}$; tear tests were performed in MD and TD. Loadextension curves are presented in Figure 6 while maximum tear-propagation force $\left(F_{\max }\right)$ and extension measured at $F_{\max }$ are included in Table 2. Tear-propagation pattern of F MD and NWF MD (Figure 6A) reveals the typical behavior of highly extensible sheet, according to ASTM D-1938 standard. ${ }^{[17]}$ In other words, both materials present an initial tear called "blip" and a maximum
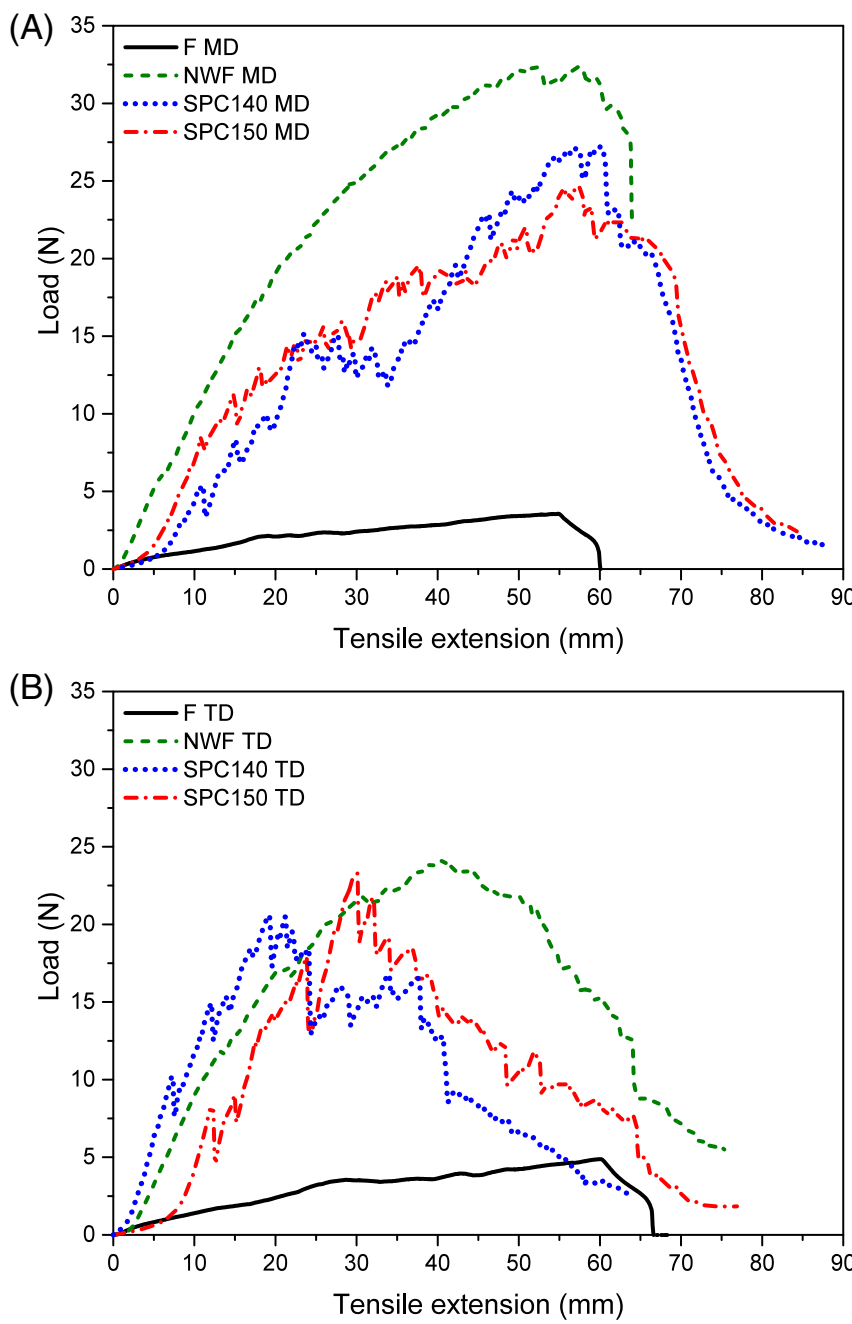

F I G U RE 6 Tearing load-extension curves for film (F), fabric (NWF), and single polymer composites (SPC140 and SPC150) determined in: (A) machine (MD) and (B) transverse (TD) direction [Color figure can be viewed at wileyonlinelibrary.com]

T A B L E 2 Tear properties ( $F_{\max }$ and ext) of film (F), fabric (NWF), and single polymer composites (SPC140 and SPC150) determined in machine (MD) and transverse direction (TD)

\begin{tabular}{lrrrrr} 
& \multicolumn{2}{l}{ MD } & \multicolumn{2}{l}{ TD } \\
\cline { 2 - 3 } Sample & $\boldsymbol{F}_{\max }(\mathbf{N})$ & ext $(\mathbf{m m})$ & & $\boldsymbol{F}_{\max }(\mathbf{N})$ & ext $(\mathbf{m m})$ \\
F & $3.5 \pm 0.5$ & $53.4 \pm 5.8$ & & $4.8 \pm 0.4$ & $60.0 \pm 1.8$ \\
NWF & $33.0 \pm 1.7$ & $53.1 \pm 3.4$ & & $25.9 \pm 2.3$ & $45.5 \pm 6.3$ \\
SPC140 & $30.8 \pm 8.7$ & $53.3 \pm 5.9$ & & $23.3 \pm 3.6$ & $28.9 \pm 6.7$ \\
SPC150 & $24.6 \pm 8.6$ & $54.2 \pm 7.8$ & & $24.5 \pm 4.8$ & $29.4 \pm 9.5$ \\
\hline
\end{tabular}

load at high extensions. F MD sample presents the lowest average $F_{\max }$ under tear testing while NWF MD, the highest. Regarding tear behavior of SPCs, both present two different kind of responses: highly extensible behavior at low extensions and lightly extensible at high 
extensions. In this case, $F_{\max }$ is determined by an average between both kinds of responses.

In order to comprehend the mechanism involved in tear behavior, photographs of all tear tested specimens are shown in Figure 7. F is more vulnerable to tearing since polymer chains are oriented as a consequence of manufacturing process. Intermolecular forces between these chains are weak, which means that the required force to propagate tearing would not be so high. On the other hand, NWF presents a more resistant behavior to tearing because of its structure: a net of fibers randomly distributed with a repetitive pattern of hot points. From Figure 7, it can be observed that F MD presents the typical tear failure, meanwhile NWF MD shows a progressive tear towards the specimen's sides (deviated from the tearing path) as a consequence of fibers net resistance. Concerning SPCs, they present an average $F_{\max }$ within the corresponding range given by $\mathrm{F}$ MD and NWF MD values, being more similar to the last ones. Additionally, the variation of $F_{\max }$ is around $30 \%$ for both SPCs (Table 2). This considerable dispersion could be attributed to variations in the adhesion degree of external films with NWF by calendering. Regarding tear propagation path, SPC140 MD presents a combination of F MD and NWF MD tearing behavior (Figure 7). It seems that external $\mathrm{F}$ layers fail first and then they take off from NWF. Consequently, NWF supports tear propagation by itself, leading to the deviation of the crack path. Even though $\mathrm{F}$ gives the initial tearing resistance to SPCs, NWF supports the greatest propagation force. On the other hand, SPC150 MD shows the same tear failure as F $\mathrm{MD}$, following the test direction. In this case, $\mathrm{F}$ are more penetrated into NWF what restricts fibers movement and avoids tear path deviation. Clearly, tear behavior differences between both SPCs proceed from processing temperature as it was observed in tensile properties results.

Regarding tearing behavior in TD (Figure 6B), $\mathrm{F}$ and NWF present similar load-extension curves as in MD, conserving the highly extensible behavior. ${ }^{[17]}$ This is also evidenced in Figure 7 where it is possible to note that tearing failure mode for F TD and NWF TD is the same as in MD. However, there is a difference in $F_{\max }$ values

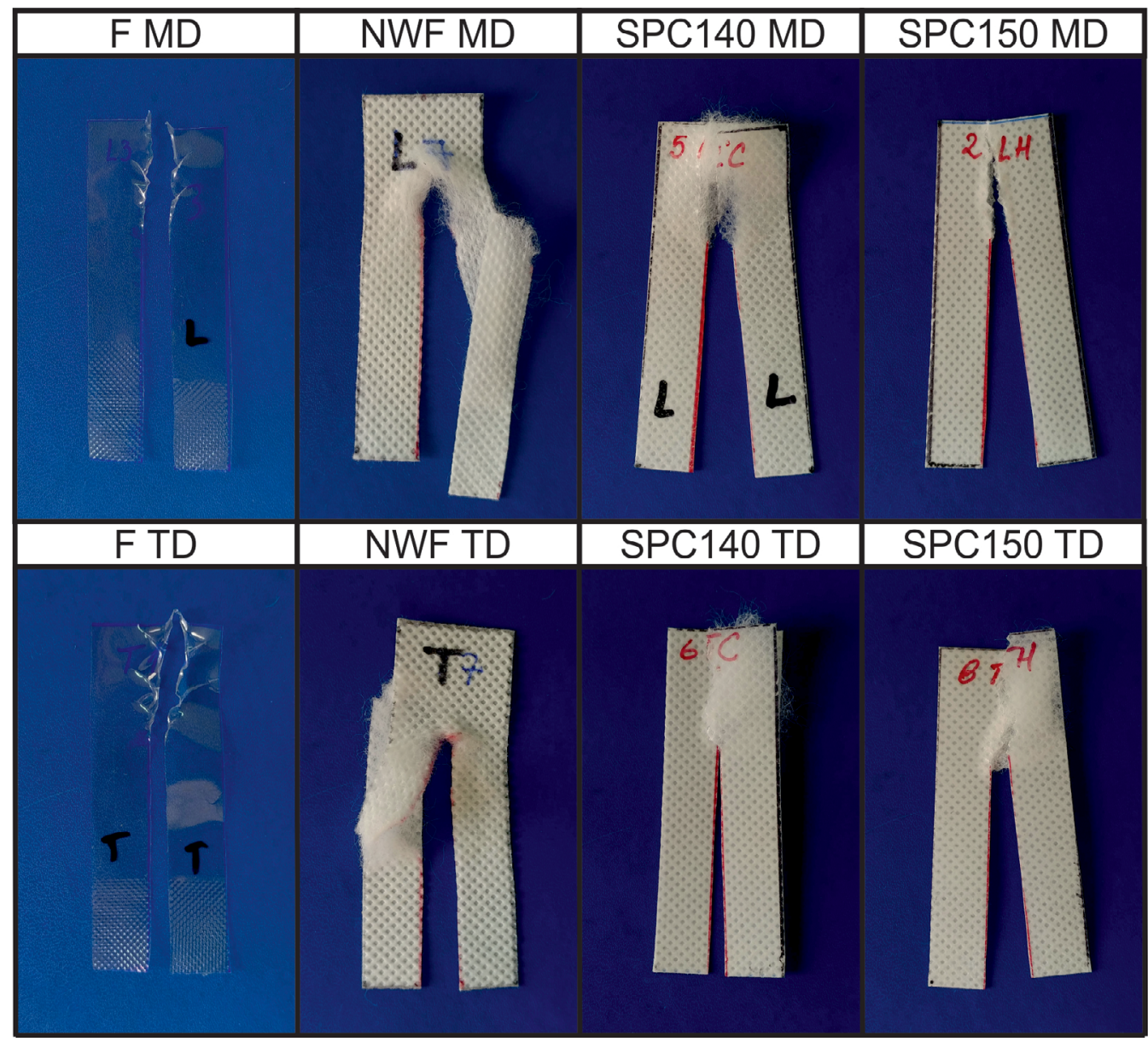

F I G U RE 7 Photographs of specimens after tear propagation test for film (F), fabric (NWF), and single polymer composites (SPC140 and SPC150) determined in machine (MD) and transverse (TD) direction [Color figure can be viewed at wileyonlinelibrary.com] 
for both samples (Table 2). In the case of $\mathrm{F}$, it is required a higher $F_{\max }$ to propagate the tear in TD with respect to MD, agreeing with previous studies found in literature. ${ }^{[36-38]}$ On the other hand, $F_{\max }$ for NWF TD is lower than the corresponding value determined in MD. Tearing behavior of SPCs present similar loadextension curves (Figure 6B) which correspond to a low extensible material, different from the observed pattern in MD. Taking into account the standard deviation of $F_{\max }$, it is possible to claim that forces determined for each SPC in TD and MD are almost the same. Also, $F_{\max }$ values are within the range given by forces measured for F TD and NWF TD, closer to the last ones, as it was observed in MD. Respect to the extension at $F_{\max }$ for SPC140 TD and SPC150 TD, their values are similar but lower $(50 \%)$ in comparison to MD ones. This fact, in addition with similar $F_{\max }$ values, allows to infer that the processing direction have more influence on tearing response than processing temperature, which also is observed for NWF tear behavior. It is important to highlight that this fact is also evidenced in tensile behavior of SPCs, as it was previous discussed.

\section{4 | CONCLUSION}

SPCs sheets based on PP from nonwoven fabric (NWF) and film (F) were obtained by hot calendering at pilot scale. In this context, two different processing temperatures $\left(140\right.$ and $\left.150^{\circ} \mathrm{C}\right)$ were used in order to analyze their influence on SPCs microstructure and final mechanical behavior. From the morphological analysis, it is possible to claim that the highest the temperature, the strongest $\mathrm{F} / \mathrm{NWF}$ interfacial adhesion and the deeper penetration of F into NWF microstructure. Additionally, it was demonstrated that NWF core remains intact after calendering in both SPCs. This fact is also evidenced in mechanical behavior where load-extension curves of SPCs present the same pattern as NWF one, being SPCs more resistant and less ductile. In this way, the study of the relationship between microstructure and final properties of SPCs allowed to assess the influence of processing temperature on the macroscopic mechanical behavior. An increment of only $10^{\circ} \mathrm{C}$ in calendering temperature can improve F/NWF adhesion. Additionally, processing direction has more influence than temperature in MD meanwhile in TD the opposite occurs. Both developed SPC sheets proved to have a differential mechanical performance with respect to $\mathrm{F}$ and also between them. These results demonstrate that obtained SPC sheets could be useful for a variety of specific applications based on their recycling capability, flexibility and low-costs. Besides, tailored properties can be achieved through a proper selection of processing temperature with sustainable and easy processability.

\section{ACKNOWLEDGMENT}

Authors want to specially thank Prof. Numa Capiati for his inspiration, guidance, and help. Prof. Capiati was a pioneer in this subject. He developed the concept of "one polymer composites" during his research stay in the University of Massachusetts (Amherst, USA) at the Materials Research Laboratory with Prof. Porter in the 1970s. Upon his return to Argentina, he founded the research group on composite materials where the authors were trained.

Thank you Numa for sharing your scientific, technological, and life knowledges in such a warm way!

\section{ORCID}

Silvia E. Barbosa (1) https://orcid.org/0000-0002-0434-

0972

\section{REFERENCES}

[1] N. J. Capiati, R. S. Porter, J. Mater. Sci. 1975, 10(10), 1671. https://doi.org/10.1007/BF00554928.

[2] S. Houshyar, R. A. Shanks, A. Hodzic, J. Appl. Polym. Sci. 2005, 96, 2260. https://doi.org/10.1002/app.20874.

[3] T. Bárány, J. Karger-Kocsis, T. Czigány, Polym. Adv. Technol. 2006, 17, 818. https://doi.org/10.1002/pat.813.

[4] D. Bhattacharyya, S. Fakirov, Synthetic Polymer-Polymer Composites, Hanser, Munich 2012.

[5] A. Pegoretti, Express. Polym. Lett. 2007, 1, 710. https://doi.org/ 10.3144/expresspolymlett.2007.97.

[6] B. Alcock, N. O. Cabrera, N. M. Barkoula, J. Loos, T. Peijs, J. Appl. Polym. Sci. 2007, 104(1), 118. https://doi.org/10.1002/ app. 24588.

[7] Á. Kmetty, T. Bárány, J. Karger-Kocsis, Prog. Polym. Sci. 2010, 35(10), 1288. https://doi.org/10.1016/j.progpolymsci.2010. 07.002 .

[8] B. Alcock, T. Peijs, Adv. Polym. Sci. 2013, 251, 1. https://doi. org/10.1007/12_2011_159.

[9] J. L. Mijares, E. Agaliotis, C. R. Bernal, M. Mollo, Polym. Advan. Technol. 2018, 29(1), 111. https://doi.org/10.1002/pat. 4093.

[10] A. Rawal, T. H. Shah, S. C. Anand, Geotextiles in civil engineering. in Handbook of Technical Textiles (Eds: A. R. Horrocks, S. C. Anand), Woodhead Publishing, Kidlington 2016, p. 111.

[11] S. Fakirov, Macromol. Mater. Eng. 2013, 298, 9. https://doi.org/ 10.1002/mame.201200226.

[12] P. J. Hine, I. M. Ward, in Mechanical properties of polymers based on nanostructure and morphology (Eds: F. J. Baltá-Calleja, G. H. Michler), CRC Press, Boca Raton, FL 2005, p. 677.

[13] C. Gao, L. Yua, H. Liu, L. Chen, Prog. Polym. Sci. 2012, 37(6), 767. https://doi.org/10.1016/j.progpolymsci.2011.09.005.

[14] F. Hassani, P. J. Martin, B. G. Falzon, AIP Conf. Proc. 2018 1960, 020010 https://doi.org/10.1063/1.5034811.

[15] ASTM D-3418:2003. Standard Test Method for Transition Temperatures of Polymers by Differential Scanning Calorimetry. 
[16] ASTM D-882:2002. Standard Test Method for Tensile Properties of Thin Plastic Sheeting.

[17] ASTM D-1938:2002. Standard Test Method for TearPropagation Resistance (Trouser Tear) of Plastic Film and Thin Sheeting by a Single-Tear Method.

[18] M. A. L. Manchado, J. Blagiotti, L. Torre, J. Kenny, Polym. Eng. Sci. 2000, 40(10), 2194. https://doi.org/10.1002/pen.11351.

[19] G. Wypich, Handbook of nucleating agents, Chemtech Publishing, Toronto 2016.

[20] L. B. Morgan, J. Appl. Chem. 1954, 4(4), 160. https://doi.org/ 10.1002/jctb.5010040403.

[21] G. Machado, E. Kinast, J. Scholten, A. Thompson, Eur. Polym. J. 2009, 45, 700. https://doi.org/10.1016/j.eurpolymj. 2008.12.015.

[22] G. Machado, E. L. G. Denardin, E. J. Kinast, M. D. C. Gonçalves, Eur. Polym. J. 2005, 41(1), 129. https://doi. org/10.1016/j.eurpolymj.2004.08.011.

[23] A. J. Lovinger, B. Lotz, D. D. Davis, Polymer 1990, 31(12), 2253. https://doi.org/10.1016/0032-3861(90)90310-U.

[24] D. A. Hanaor, C. C. Sorrell, J. Mater. Sci. 2011, 46(4), 855. https://doi.org/10.1007/s10853-010-5113-0.

[25] R. I. Bickley, T. Gonzalez-Carreno, J. S. Lees, L. Palmisano, R. J. D. Tilley, J. Solid State Chem. 1991, 92(1), 178. https://doi. org/10.1016/0022-4596(91)90255-G.

[26] J. Murphy, Additives for plastics handbook, Elsevier, Great Britain 2001.

[27] A. A. El-Ghor, M. M. Noshy, A. Galal, H. R. Mohamed, Toxicol. Sci. 2014, 142(1), 21. https://doi.org/10.1093/toxsci/ kfu157.

[28] G. Q. Liu, Z. G. Jin, X. X. Liu, T. Wang, Z. F. Liu, J. Sol-Gel Sci. Techn. 2007, 41(1), 49. https://doi.org/10.1007/s10971-0060122-9.
[29] F. Rybnikar, J. Appl. Polym. Sci. 1989, 38, 1479. https://doi. org/10.1002/app.1989.070380806.

[30] M. Alonso, J. I. Velasco, J. A. de Saja, Eur. Polym. J. 1997, 33 (3), 255. https://doi.org/10.1016/S0014-3057(96)00159-0.

[31] K. R. Espinosa, L. A. Castillo, S. E. Barbosa, Mater. Des. 2016, 111, 25. https://doi.org/10.1016/j.matdes.2016.08.045.

[32] L. E. Nielsen, R. F. Landel, Mechanical properties of polymers and composites, CRC Press, New York 1993.

[33] F. Sadeghi, A. Ajji, P. J. Carreau, J. Plast. Film Sheet. 2005, 21 (21), 199. https://doi.org/10.1177/8756087905057085.

[34] R. Ridruejo, C. González, J. Llorca, Int. Solids Struct. 2011, 48, 153. https://doi.org/10.1016/j.ijsolstr.2010.09.013.

[35] E. Andreasson, N. Mehmood, S. Kao-Walter. 2013. In 13th International Conference on Fracture. ICF13. http://urn.kb. se/resolve?urn=urn:nbn:se:bth-6920.

[36] N. Mehmood, T. Mao, G. Bhupati, Master's Degree Thesis. Blekinge Institute of Technology, Sweden, 2012.

[37] S. H. Tabatabaei, P. J. Carreau, A. Ajji, Polymer 2009, 50(17), 4228. https://doi.org/10.1016/j.polymer.2009.06.071.

[38] A. C. Chang, S. P. Chum, A. Hiltner, E. Baer, Polymer 2002, 43 (24), 6515.

How to cite this article: Vazquez YV, Castillo LA, Barbosa SE. Single polymer composite sheets from polypropylene nonwoven fabric and films. Influence of processing conditions on final properties. Polymer Composites. 2020;1-10. https:// doi.org/10.1002/pc.25511 